\title{
Proactive Versus Reactive Seismic Monitoring in Mines — Results of a Seismic Monitoring Survey
}

\author{
M.R. Hudyma Itasca Consulting Canada Inc., Canada \\ D. Heal Australian Centre for Geomechanics, Australia
}

\begin{abstract}
A survey was undertaken to examine the use of seismic monitoring in mines. The 20-question survey titled "Application of Seismic Monitoring" (ASM) was used for rating the design and operation of seismic systems, and the application of seismic data. The survey indicated that the design, operation and data processing is relatively well conducted at most mines. However, data analysis and data interpretation are often not as well undertaken. Possible reasons for the lack of data analysis and data interpretation could be: lack of acceptance of mine seismology techniques, insufficient training, inadequate analysis tools, or lack of time to conduct the analyses. Mines that score well on the ASM survey tend to use their seismic systems proactively to understand the seismicity problem in their mines. Mines that score below average on the ASM survey tend to use seismic monitoring almost entirely as a reactive tool. The survey results for the 33 mines have been summarised to provide a means of benchmarking site practice against general practice in Australia and Canada.
\end{abstract}

\section{Introduction}

Seismic monitoring in mines is used widely in Australia and Canada, with more than 40 minewide systems currently in operation between the two countries. In most cases, seismic monitoring is used in mines in which large seismic events result in rock mass damage posing safety risks, and requiring rehabilitation, resulting in increased mining costs and lower mine productivity. However, in some mines, rockburst damage is not a primary concern, but monitoring of mining-induced seismic events is used as a rock mass monitor. This has become increasingly popular in caving mines, where seismic events are used to monitor the propagation of caving in the mine.

It is widely documented that there are many potential techniques for analysing seismic events to understand mining-induced seismicity. However, many mines do not use their seismic data to its greatest potential. The amount of effort and resources given to seismic monitoring is often directly related to the severity of the seismicity related problem. Generally, the more effort and resources put into the seismic system, the greater the benefits realised by the mining operation. When limited resources are put into the system, its application tends to be reactive. The seismic system is used, after large events, to establish event locations and magnitudes. When adequate resources are applied to seismic monitoring, the understanding of the seismic problem is often greatly improved, ultimately resulting in a better understanding of the mechanisms of seismicity in the mine. This permits the mine to start to proactively manage the seismic problem.

A survey of seismically active mines with currently operational seismic systems was created. The goals of the survey were to:

- Identify the strengths and weaknesses with regard to the design, operation and performance of a seismic system.

- Identify trends in seismic monitoring in mines and identify aspects of seismic monitoring that require further application and development.

- Provide a means of benchmarking the performance and effectiveness of a seismic system. 


\section{Survey}

\subsection{Introduction}

A 20-question survey was built to investigate the application of seismic systems in underground, hardrock mines (Table 1). The "Application of Seismic Monitoring" (ASM) survey covers the main topics of practical seismic monitoring in mines, focussing on four main themes: design and operation of the seismic system, data processing, data analysis, and data interpretation.

Each of the 20 questions addresses a topic with regard to how the seismic system is used at the mine. A positive answer is related to the better application of an aspect of seismic monitoring. Ultimately, the number of positive answers is summed to get a total score out of 20 . The higher the sum the better the operation of the seismic system and the better the seismic data is being utilised.

\subsection{Survey questions}

Each of the survey questions is discussed, along with the rationale for the questions, and guidance on how to answer the questions.

\subsubsection{Seismic system design and operation}

A seismic monitoring system is a 24-hour a day monitor providing data about the rock mass response to mining. There are six survey questions related to the design and operation of the seismic monitoring system.

Question 1 - Is the entire mine monitored by the seismic system?

In some mines, only a portion of the mine, or a problematic part of the mine is effectively monitored with the seismic system. Parts of the mine are effectively un-monitored, or the seismic system gives only rudimentary results. While limited monitoring may achieve some requirements of the seismic system, it limits the minewide understanding of the problem and often only provides a partial picture of the seismic response to mining.

Answer YES if the entire mine is covered by the seismic system. Answer NO if active parts of the mine do not have sensors.

\section{Question 2 - Is the seismic system repaired immediately if there are serious problems?}

An underground mine is a hostile environment for seismic monitoring systems. Mine equipment, blasting and rock movement often result in damage to components of the seismic monitoring system, particularly wiring and communications. Consequently, seismic monitoring systems require routine maintenance.

In some mines, the seismic monitoring system is an essential component in the management of seismic risk. In these mines, if a component of the system is damaged or non-operational, a high priority is put on getting the seismic system fixed, irrespective of the cost or difficulty of the repair. For these mines, the availability of the seismic system often exceeds $98 \%$.

In other mines, the seismic monitoring system has a much less important role. In these mines, if components of the seismic system are damaged, the time to get the system operation may be considerable, particularly if expensive replacement components are required. During the intervening period, the quality of the seismic data may be greatly diminished.

Answer YES if the system is typically repaired quickly when damaged or when communications is lost. There should be greater than $98 \%$ availability for the system. Answer NO if parts of the system are not in operation for extended periods of time, or if system availability is less than $98 \%$, or routine repairs typically take weeks or months to occur. 
Table 1 Questions in the Application of Seismic Monitoring (ASM) survey

\begin{tabular}{|c|c|c|c|c|}
\hline & No & & & Yes \\
\hline \multirow{6}{*}{ 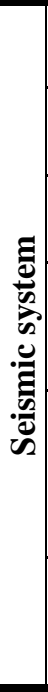 } & & $\begin{array}{l}\text { 1. Only localised areas of the mine are } \\
\text { adequately monitored by the seismic system. }\end{array}$ & $\begin{array}{l}\text { 1. The entire mine is monitored by the seismic } \\
\text { system. }\end{array}$ & \\
\hline & & $\begin{array}{l}\text { 2. Parts or all of the seismic system is regularly } \\
\text { down. }\end{array}$ & $\begin{array}{l}\text { 2. The seismic system is repaired immediately if } \\
\text { there are serious problems. }\end{array}$ & \\
\hline & & $\begin{array}{l}\text { 3. P and } \mathrm{S} \text { wave velocity have not been } \\
\text { measured in situ }\end{array}$ & $\begin{array}{l}\text { 3. P and } \mathrm{S} \text { wave velocity have been measured in } \\
\text { situ }\end{array}$ & \\
\hline & & $\begin{array}{l}\text { 4. Essentially only uniaxial sensors are used. } \\
\text { There are less than } 3 \text { triaxial sensors in the } \\
\text { mine. }\end{array}$ & $\begin{array}{l}\text { 4. There are an adequate number of triaxial } \\
\text { sensors in the mine. } 3 \text { for a small mine. } 5 \text { or } \\
\text { more for a larger mine. }\end{array}$ & \\
\hline & & $\begin{array}{l}\text { 5. Magnitude scale or source location issues. } \\
\text { The local magnitude scale is deemed } \\
\text { unreliable or often saturates. Event locations } \\
\text { are often unstable or inaccurate. }\end{array}$ & $\begin{array}{l}\text { 5. The magnitude scale and source locations are } \\
\text { good. There is a reliable magnitude scale for } \\
\text { the mine rarely saturates. Most events are } \\
\text { accurately located. }\end{array}$ & \\
\hline & & $\begin{array}{l}\text { 6. There is no seismic system upgrade plan. The } \\
\text { seismic sensor array does not keep up with } \\
\text { mining. }\end{array}$ & $\begin{array}{l}\text { 6. There is a seismic system upgrade plan on a } \\
\text { regular/yearly basis to keep the system up-to- } \\
\text { date with nearby mining. }\end{array}$ & \\
\hline \multirow{3}{*}{ 丞 } & & 7. Data processing is not kept up to date. & $\begin{array}{l}\text { 7. Data is processed and checked on a daily } \\
\text { basis. }\end{array}$ & \\
\hline & & $\begin{array}{l}\text { 8. Nobody looks at the seismic system if the } \\
\text { regular operator is away. }\end{array}$ & $\begin{array}{l}\text { 8. The seismic system has an operator on all } \\
\text { normal work days. }\end{array}$ & \\
\hline & & 9. Data is not processed 24 hours per day. & $\begin{array}{l}\text { 9. There is a seismic system operator } 24 \text { hours } \\
\text { per day. }\end{array}$ & \\
\hline \multirow{5}{*}{ 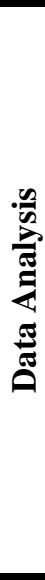 } & & $\begin{array}{l}\text { 10. Events are plotted on mine plans that are out } \\
\text { of date or don't include geology information. }\end{array}$ & $\begin{array}{l}\text { 10. Events are plotted on mine plans that are } \\
\text { routinely updated and include geology } \\
\text { information. }\end{array}$ & \\
\hline & & $\begin{array}{l}\text { 11. Routine back-analysis of seismic data is } \\
\text { rarely done. It only occurs following large } \\
\text { seismic events. }\end{array}$ & $\begin{array}{l}\text { 11. Past seismic data is routinely analysed } \\
\text { (weekly/monthly) for location, frequency- } \\
\text { magnitude and trends over time. }\end{array}$ & \\
\hline & & $\begin{array}{l}\text { 12. Frequency-magnitude relations have not } \\
\text { been investigated or established for the mine. }\end{array}$ & $\begin{array}{l}\text { 12. Frequency-magnitude relation is monitored } \\
\text { on a minewide basis and for individual } \\
\text { regions of the mine. }\end{array}$ & \\
\hline & & $\begin{array}{l}\text { 13. There is little or no analysis of individual } \\
\text { seismic sources in the mine. }\end{array}$ & $\begin{array}{l}\text { 13. Seismic data is regularly analysed to } \\
\text { identify seismic sources and seismic source } \\
\text { mechanism using established techniques. }\end{array}$ & \\
\hline & & $\begin{array}{l}\text { 14. Daily seismic trend analysis is not done or is } \\
\text { only rarely undertaken. }\end{array}$ & $\begin{array}{l}\text { 14. Time history or trend analysis of seismic } \\
\text { source parameters is completed most days. }\end{array}$ & \\
\hline \multirow{6}{*}{ 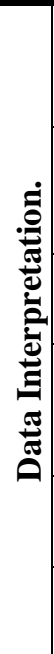 } & & $\begin{array}{l}\text { 15. No routine, written reporting or } \\
\text { interpretation of seismicity in the mine. }\end{array}$ & $\begin{array}{l}\text { 15. Monthly reports include an interpretation of } \\
\text { the seismicity, and cause-effect relations in } \\
\text { the seismicity. }\end{array}$ & \\
\hline & & $\begin{array}{l}\text { 16. No established procedures for re-entry } \\
\text { following blasts and large events. }\end{array}$ & $\begin{array}{l}\text { 16. Re-entry and exclusion periods following } \\
\text { blasts and large events have been } \\
\text { established based on local seismic data. }\end{array}$ & \\
\hline & & $\begin{array}{l}\text { 17. Source parameters other than location and } \\
\text { magnitude are rarely investigated. }\end{array}$ & $\begin{array}{l}\text { 17. Seismic source parameters are regularly } \\
\text { investigated. }\end{array}$ & \\
\hline & & $\begin{array}{l}\text { 18. Seismic data is not analysed in conjunction } \\
\text { with other rock mechanics or numerical } \\
\text { modelling information. }\end{array}$ & $\begin{array}{l}\text { 18. Seismic data is compared with other } \\
\text { instrumentation and numerical modelling. }\end{array}$ & \\
\hline & & $\begin{array}{l}\text { 19. Seismic data and information is rarely used } \\
\text { in mine planning decisions. }\end{array}$ & $\begin{array}{l}\text { 19. Seismic data and information is routinely } \\
\text { used in mine planning decisions. }\end{array}$ & \\
\hline & & $\begin{array}{l}\text { 20. No routine analysis or interpretation to } \\
\text { investigate seismic hazard in the mine. }\end{array}$ & $\begin{array}{l}\text { 20. Seismic hazard is a key objective of data } \\
\text { interpretation and is routinely undertaken. }\end{array}$ & \\
\hline
\end{tabular}


Question 3 - Have the P and S wave velocity been measured in situ?

The p-wave velocity in hardrock is typically in the range of $6000 \mathrm{~m}$ per second, while the s-wave velocity is typically about $3500 \mathrm{~m}$ per second. However, these values depend on a number of factors, including: lithology, rock mass structure and stress environment. In situ p-wave velocity can vary from less than $5000 \mathrm{~m}$ per second to more than $6500 \mathrm{~m}$ per second. To get accurate source locations, the p-wave and s-wave velocities need to be measured in situ with blasting.

The in-situ p-wave and s-wave velocity can be easily back-calculated if the exact location of a blast is known. Ideally the blast location should be known within about $0.5 \mathrm{~m}$. The distance from the blast to each of the sensors is calculated and plotted against the absolute or relative arrival time recorded on the seismic system (Figure 1). The velocity is simply the slope of the best-fit line. The blast may be a dedicated blast for checking the velocity, but any blast can be used as long as the location is known and the p-wave can be clearly picked on the seismic system. Development mining blasts are ideal for back-calculation, as the cut location (where the blast is initiated) can be surveyed, giving a blast location with less than a $0.5 \mathrm{~m}$ error.

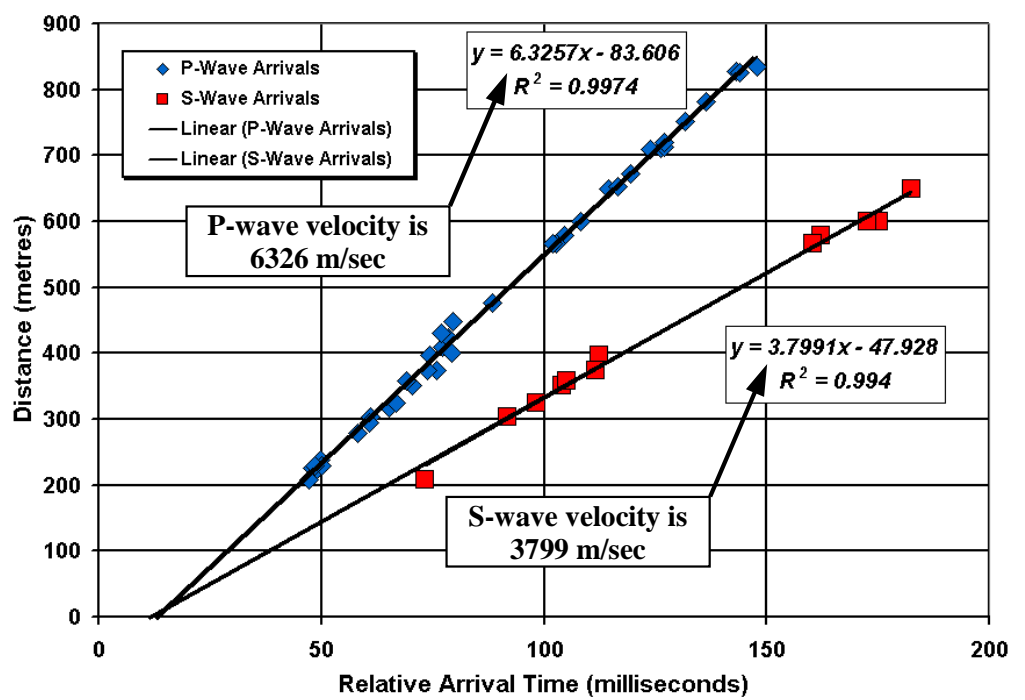

Figure 1 P-wave and s-wave velocities can be calculated by plotting the distance from the blast to each seismic sensor versus the relative arrival time to each sensor

Answer YES if the in situ velocity has been measured. Answer NO if the in situ seismic velocity has not been checked, or if it is suspected that the sonic velocities being used are not accurate.

Question 4 - Are there an adequate number of triaxial sensors in the mine?

Triaxial sensors are used to estimate seismic source parameters for individual seismic events. Seismic source parameters are used to better understand seismic hazard and seismic source mechanism in mines. Determining seismic source parameters with a single triaxial sensor is insufficient. The ground motion measured by any one seismic sensor may be affected by radiation pattern, travel path and local sensor effects, making the calculated source parameters unreliable. Ideally, for a small mine, a minimum of three triaxial sensors is required to get stable and reliable source parameters. For larger mines, five or more triaxial sensors may be required. Some of the largest mines have more than 20 triaxial sensors in the seismic array.

Answer YES if there are at least 3 triaxial sensors installed and routinely operational for a smaller mine, or at least 5 triaxial sensors installed for a larger mine. A small mine is arbitrarily defined as having the longest dimension of the mine being less than $600 \mathrm{~m}$ in length. Answer NO if the number of triaxial sensors is too low.

\section{Question 5 - Are the source locations and magnitude scale reliable?}

Accurate source locations and reliable seismic source parameters are fundamental to getting maximum value from a seismic system. If source locations are inaccurate, it will be difficult to identify seismic sources in the mine. Data analysis and interpretation techniques will be less conclusive. Inaccurate source locations: will 
not cluster well spatially, will often locate in unrealistic locations (in voids or far from mining areas), may have a systematic location error (too far into the footwall or orebody, or have an unrealistic elevation), or will move significantly in space depending on which sensors are used (ideally a stable source location should not move significantly if a few sensors are rejected).

Unreliable seismic source parameters tend to: not follow a reasonable frequency-magnitude relation, vary significantly depending on which triaxial sensors are used, or will have a scattered energy-moment relation.

Answer YES if the source locations and seismic source parameters are consistent and reliable. Answer NO if locations or seismic source parameters are inconsistent or unreliable.

Question 6 - Is there a seismic system upgrade plan on a regular/yearly basis to keep the system up-to-date with nearby mining?

Mining operations tend to start in one part of the orebody, and migrate to other parts of the orebody over time. Most seismic events occur in proximity to active mining, particularly stope mining. To adequately cover new mining areas, the sensor array needs to be adjusted. When designing a seismic system, consideration needs to be given for where mining is likely to occur over the next few years. It is surprising to note the number of seismic systems that are installed around current workings, but have no plan for the mining areas in the next few years.

Answer YES if there is a plan to move sensors to keep up with mining. Answer NO if there is no plan to move sensors, or if sensors are poorly monitoring the active mining areas.

\subsubsection{Data processing}

\section{Question 7 - Is seismic data processed and kept up-to-date?}

In most mines, seismic data is processed daily and blasts, outliers and non-events removed from the database. If seismic data is not kept up-to-date, blasts and outlier events will likely pollute the seismic database, making it difficult to analyse seismic data for trends. In this situation, the seismic system is truly only a reactive monitoring system. When a large event occurs, it is located and reactive operational mining decisions are made. Otherwise, the seismic system provides minimal value to proactive understanding of the seismic problem at a mine.

Answer YES if blasts are consistently removed from the seismic record and larger events are manually checked to ensure good locations. Answer NO if the seismic system operator does not manually check that blasts are removed, or if larger events are not manually checked.

\section{Question 8 - Does the seismic system have an operator on all normal work days?}

Some mines do not have a seismic system operator on a daily basis. It may be that the seismicity problem does not justify the need for a daily operator, or it may be that trained staff are not available. This is sometimes the case in fly-in-fly-out mining operations, where there is an operator for only eight or nine days out of every fourteen. The consequence of not having a daily seismic system operator is that there is limited ability to react to abnormal seismicity as it occurs in the mine. In addition, if there is a problem with the seismic system, the problem may go un-noticed for a considerable period of time, with the potential to compromise the collection of quality seismic data.

Answer YES if the seismic system and data is checked on most normal work days. Answer NO if the seismic system is not checked on most work days.

\section{Question 9 - Is there a seismic system operator processing data 24 hours per day?}

Some mines with severe rockbursting problems have a seismic system operator processing seismic data 24 hours a day. Seismic system operators are typically trained to monitor for unusual changes or for patterns in seismicity that may be related to the occurrence of large or damaging events. Information can be passed on in real time to mine operations, potentially allowing high risk workplaces to be closed proactively.

Answer YES if there is an on-site seismic system operator 24 hours a day. Answer NO if there is not a seismic system operator on-site 24 hours a day. 


\subsubsection{Data analysis}

Question 10 - Are events plotted on mine plans that are routinely updated and include geology information?

For mining-induced seismicity, accurate locations is the most important seismic source parameter (Brummer, 1999). Accurate spatial location of seismic data on mine plans frequently identifies the location of seismic events near geological structures, or mine structures such as stopes and pillars (Leslie and Vezina, 2001; Amidzic, 2001).

Answer YES if events are routinely plotted on up-to-date mine plans that include major geological structures. Answer NO if: events are not plotted routinely, or the mine plans are more than a few months outof-date, or if the mine plans do not include the major geological structures.

Question 11 - Is past seismic data routinely (weekly to monthly) analysed for location and trends over time?

Future seismicity in a mine is strongly related to past seismicity in a mine. One of the greatest opportunities to become proactive about mine seismicity hazards and risk is through routine back-analysis and interpretation of seismic data. Despite this, routine seismic data analysis is often not undertaken.

In our experience the greater the amount of seismic analysis conducted, the faster and better the operator becomes at doing the analysis and interpreting the results. This will lead to a better understanding of the local seismic response to mining, as well as the capabilities and limitations of the seismic monitoring system.

Alternatively, if seismic data is not routinely analysed, it is possible that a data collection problem will arise in the seismic monitoring and go undetected for an extended period of time. Only when it is suddenly important to analyse the seismic data, is it realised that there is a monitoring problem, or that the data is inadequate.

Answer YES if past seismicity is analysed at least monthly for location, and source parameter trends. Answer NO if minewide seismicity is not analysed for locations and source parameters at least monthly.

Question 12 - Is a frequency-magnitude relation monitored on a minewide basis and for individual regions of the mine?

Frequency-magnitude relations are the basis for quantitative seismic hazard analysis. On a minewide scale, the frequency-magnitude relation is important as it shows the reliability and range of applicability of the magnitude scale used at the mine. Frequency-magnitude relations are commonly monitored for different regions of the mine to spatially identify areas of higher and lower seismic hazard.

Answer YES if frequency-magnitude relations have been made for the whole mine and individual areas of the mine. Answer NO if frequency-magnitude relations have not been made for the whole mine and for individual areas of the mine.

Question 13 - Is seismic data analysed to identify seismic sources and seismic source mechanism using established techniques?

Seismicity in a mine may look conceptually similar to the diagrammatic sketch in Figure 2(left). The different symbols represent events of different magnitudes. There will be numerous individual seismic sources in a mine as suggested in Figure 2(right). Importantly, the seismicity at each seismic source is a result of the local failure mechanism, with each seismic source potentially having a different seismic hazard potential (largest possible event). Individual spatial groups of seismic events can be analysed to understand local seismic hazard and seismic source mechanism. 


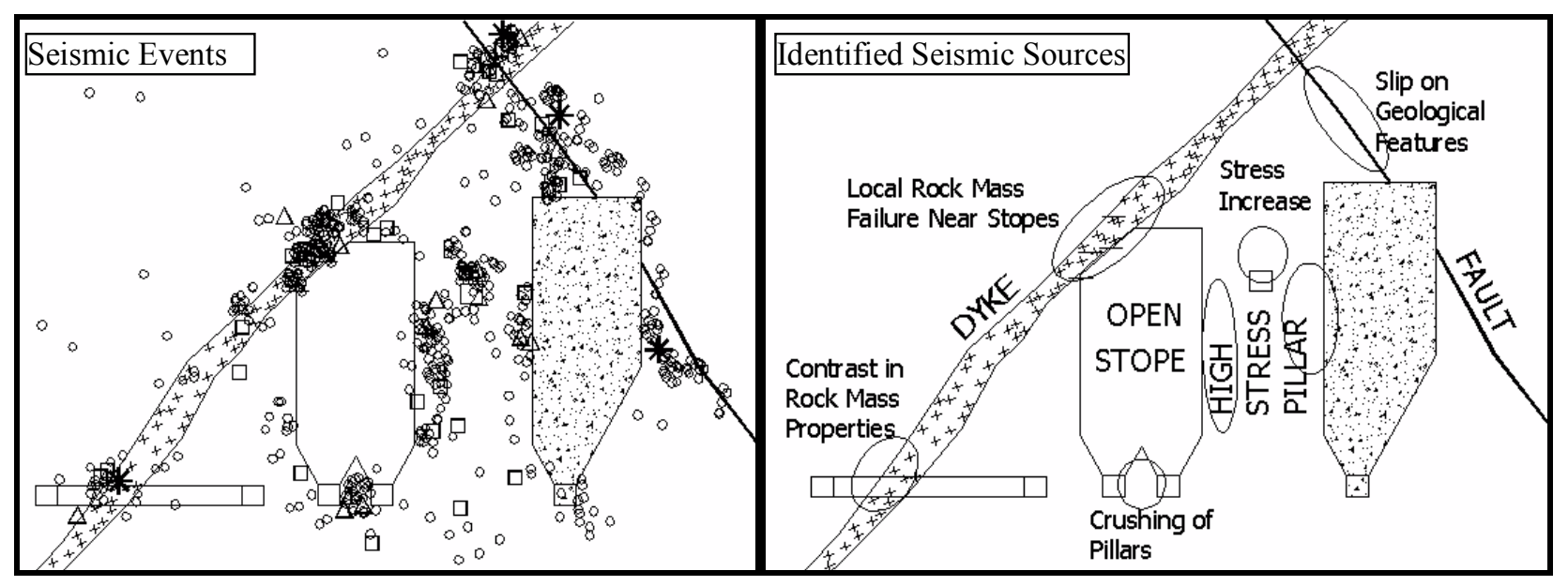

Figure 2 Conceptual seismic events around a proto-typical underground open stope mine (left). Each group of seismic events represents a separate seismic source (right) (after Hudyma et al., 2003)

Answer YES if individual seismic sources have been identified and investigated with seismic source parameters. Answer NO if individual seismic sources have not be identified and analysed with seismic source parameters.

Question 14 - Are time history or trend analysis of seismic source parameters completed most days?

There is a strong relation between mining activities and induced seismicity. Daily trends in seismic source parameters can be used to develop a better understanding of the cause and effect seismic response to mining. Plotting of event frequency, event magnitude, changes in apparent stress or energy index can give valuable insight into the relation between mining and seismicity.

Answer YES if daily event trends or time histories of seismic activity are investigated on a routine (daily) basis. Answer NO if event trends or time histories are rarely or never plotted on a daily basis.

\subsubsection{Data interpretation}

Question 15 - Are monthly reports written, including an interpretation of the seismicity, and cause-effect relations in the seismicity?

In our opinion the Achilles Heal of seismic monitoring is written reports. Many of the most notable successes at understanding and managing seismicity and rockbursting in mines have come through detailed study and documentation of seismic data. Through detailed analysis of past seismicity, trends in rock mass behaviour are identified, which leads to a broader understanding of the rock mass response to mining.

Formal monthly seismic reports are an essential means of disseminating information about recent seismicity to other members of the mine planning and mine operations teams. Creating monthly seismic reports also encourages the writer to:

- Evaluate events of the last month in a more objective context by looking at a longer time frame.

- Look for trends and cause-effect relations in the data.

- Compare the seismic response to the mining activities in the month.

Monthly reports also encourage other members of the engineering and geology departments to offer ideas, additional information, and potential causes leading to trends associated with seismicity and rockbursting. A typical monthly report should include:

- Listing of all large events and a brief discussion of the suspected causes of the events. 
- Listing of all damaging seismic events and the support system that was damaged (this will help to document the performance of support systems under dynamic loading and identify potential ground support issues).

- Long term seismic trend analysis for each sector of the mine, such as a histogram of the number of events per month over the last 12 months.

- Plans and sections showing the most seismically active areas of the mine.

Answer YES if monthly seismic reports are normally written and circulated to engineering and senior mine operations personnel. Answer NO if monthly seismic reports are not routinely written and circulated.

Question 16 - Have re-entry and exclusion periods following blasts and large events been established based on local seismic data?

One of the most common applications of seismic data is to establish locally based re-entry times following mine blasts in seismically active parts of the mine. Some mines have developed very sophisticated exclusion zones and re-entry procedures based on past seismicity.

Answer YES if seismic data has been used to develop local re-entry times and exclusions zones following mine blasts. Answer NO if local seismic data has not been used to develop re-entry times and exclusion zones.

\section{Question 17 - Are seismic source parameters regularly investigated?}

There are essentially five independent seismic source parameters: location, time of occurrence, seismic moment, seismic energy and source size (Mendecki et al., 1999). Most of the other seismic source parameters and mine seismicity parameters are derivations of these five basic parameters. There are more than 50 published seismic source parameters and mine seismicity parameters. Some of these parameters are fundamental to understanding seismicity in mines, while others are less well accepted by mine site operators and potentially less valuable in managing seismicity and rockburst hazards at minesites.

There are a number of seismic source parameter analyses that can give valuable insight into understanding seismicity in mines. For instance:

- $\mathrm{S}: \mathrm{P}$ energy ratio is strongly related to seismic source mechanism.

- Diurnal, or time of day, analysis is related to seismic source mechanism.

- Frequency-magnitude analysis is the fundamental means of assessing seismic hazard.

- Apparent stress gives indications of the level of stress acting in a rock mass.

- Seismic moment is related to the coseismic deformation occurring with a seismic related rock mass failure.

Answer YES if seismic source parameters are regularly used to understand the seismic response to mining. Answer NO if individual seismic source parameters have not be used or are only used on rare occasions (a few times a year or less).

Question 18 - Is seismic data compared with other instrumentation and numerical modelling?

Seismic analyses and interpretation are always more meaningful and useful when they are compared and correlated with other rock mechanics information including:

- Underground observations of rock mass damage.

- Physical instrumentation such as stress cells and extensometers, borehole camera information, convergence measurements.

- Results from three-dimensional numerical modelling.

Answer YES if seismic data has been compared to other rock mechanics information such as: instrumentation, underground observations or numerical modelling results. Answer NO if seismic data has not been compared other rock mechanics information. 
Question 19 - Are seismic data and related information routinely used in mine planning decisions?

Many mines use past seismic history to determine stope sequencing, development location, blasting practices and many other mine design parameters. In some cases, formal mine design rules have been created based on past seismicity (Mikula and Lee, 2002). Including the influence of seismicity in mine design and mine planning is one of the most important outcomes of proactive use of seismic monitoring.

Answer YES if past seismicity is actively used in the mine design and mine planning process. Answer NO if consideration of seismicity is not generally an input in mine design and mine planning.

\section{Question 20 - Is seismic hazard analysis a key objective of data interpretation and routinely undertaken?}

In rockburst prone mines, seismic hazard assessment is often the main technical objective of seismic monitoring. Essentially, seismic hazard is the likelihood of occurrence of seismic events, particularly large events. Seismic hazard is a complex problem in a mine as it varies in time and space. There are times when large events are more prone to occur, and there are locations in a mine that are much more prone to experience large events. At the same time, there are parts of a mine that will never experience a large event. Proactive use of seismic data identifies areas and time periods in which seismic hazard is elevated. Seismic hazard assessment typically involves detailed analysis of frequency-magnitude relations and time history plotting of seismic source parameters.

Answer YES if seismic hazard assessment is one of the key objectives of seismic data interpretation and this work is undertaken routinely (at least monthly). Answer NO if seismic hazard assessment is not undertaken at least on a monthly basis.

\section{Survey results}

\subsection{Results}

Data was collected for 33 mines, primarily in Canada, and Australia and South America during 2006. Some historical data was used, however, most of the results came from currently active mines. The ASM score for all of the mines is plotted in a bar chart and cumulative frequency distribution in Figure 3. The average ASM score was 9.6, with results varying from 1 to 18. The median ASM score was 11.

The survey results do not follow a normal or Poisson's distribution. There is a peak of results at scores around 5 and a second peak at about 12, suggesting that there may be two different populations of results in the survey.

Some of the lower scores are related to mines that have installed a small, evaluation seismic system. To determine if a minewide seismic system is required, it is relatively common in Australia to install a small system (typically 6 sensors) in part of the mine to evaluate the amount of seismicity in the mine. These systems typically cover only part of the mine and are usually batch processed off-site by geomechanics consultants. Due to the short-term scope of these temporary systems, they are less likely to score well on this survey. For seismic systems that only cover part of the mine (answered "no" to Question 1), the average ASM score was 6.7, while minewide seismic systems had an average ASM score of 10.9. The lower peak in Figure 3 is basically due to lower ASM scores associated with temporary and non-minewide seismic monitoring systems. 


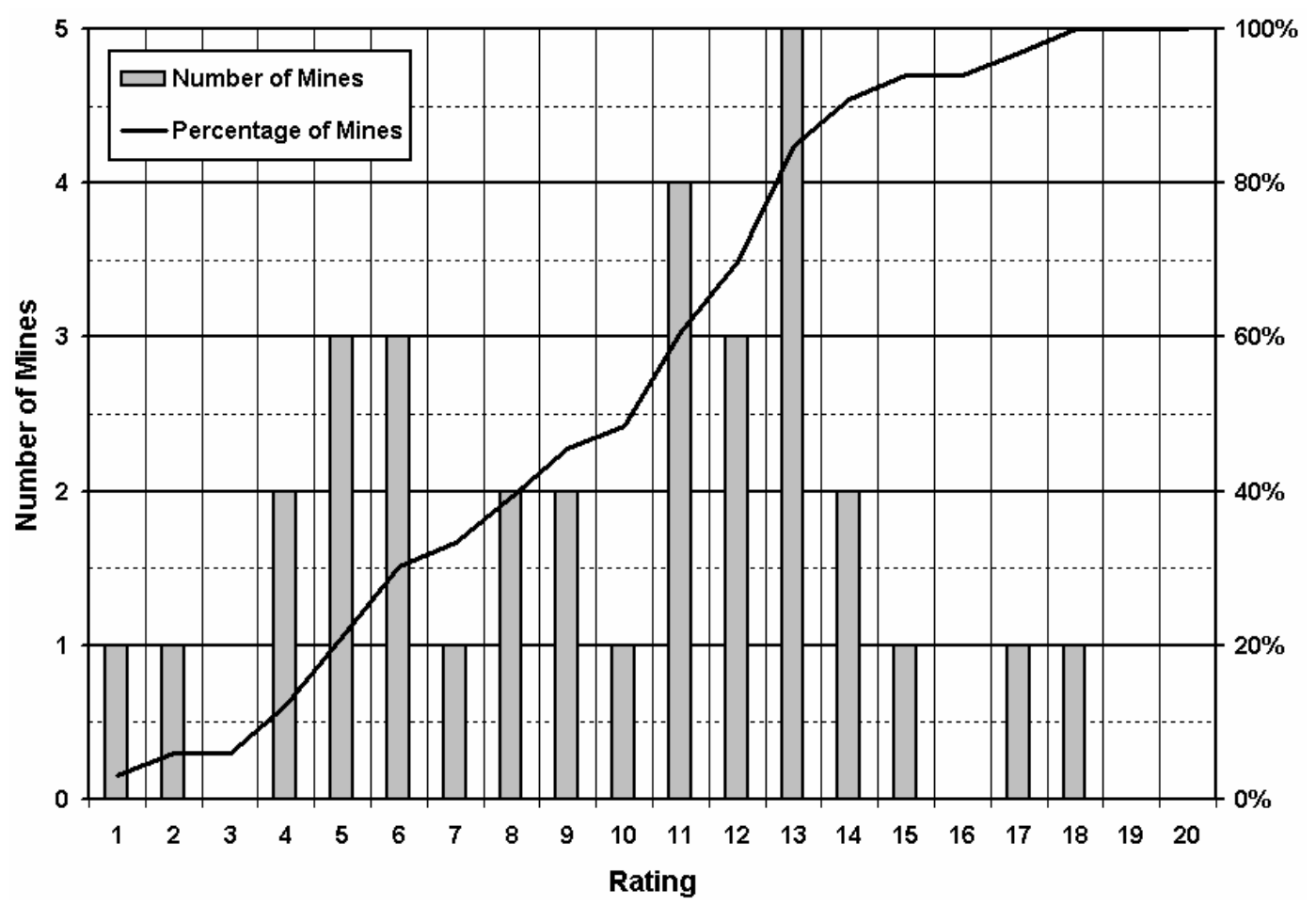

Figure 3 Results of the “Application of Seismic Monitoring” survey for 33 mines

\subsection{Discussion}

\subsubsection{Survey reliability}

A test of internal reliability was conducted on the "Application of Seismic Monitoring" survey. An internal reliability test is a means of measuring that there is consistency between the individual question results and the overall survey results. Cronbach's Alpha (Cronbach, 1951) was used to test the survey, where alpha is:

$$
\alpha=\frac{N}{N-1}\left(\frac{\sigma_{X}^{2}-\sum_{i=1}^{N} \sigma_{Y_{i}}^{2}}{\sigma_{X}^{2}}\right)
$$

where:

$\mathrm{N}$ is the number of questions.

$\sigma^{2}$ is the variance of the test scores for all of the tests.

$\sigma^{2} \mathrm{Yi}$ is the variance for sample $\mathrm{i}$ for test question $\mathrm{Y}$.

For the entire 20-question survey, internal consistency is very good $(\alpha=0.82)$. For the first 9 questions, and questions 10 through 20, is also good with $\alpha=0.70$ and 0.76 , respectively. Essentially, the reliability test shows that the score for individual survey questions is consistent with and correlate well with the overall survey results.

\subsubsection{Seismic data collection}

The first nine questions of the survey focus on how seismic data is collected and processed. Figure 4 is a histogram of the results from the mines, for the first 9 questions. The average score is 5.2. Within the context of the survey, a relatively low score is less than 5 and a relatively good score is 7 or more.

Overall, the results suggest that seismic systems are generally well designed and operated, and that the seismic data is adequately processed. The questions that had the fewest positive responses were: 
- Question 5 - Unreliable locations and magnitude scale. Only 16 of the 33 responses felt that the seismic source locations were accurate and that the magnitude scale was reliable. This suggests that many mines have issues with regard to the accuracy of source location, or find that the magnitude assessment by the seismic system is not adequate.

- Question 9-24 hour per day seismic operator. The seismic system is attended 24 hours a day, and the data is processed 24 hours a day. Only 1 of the mines had a seismic operator 24 hours a day.

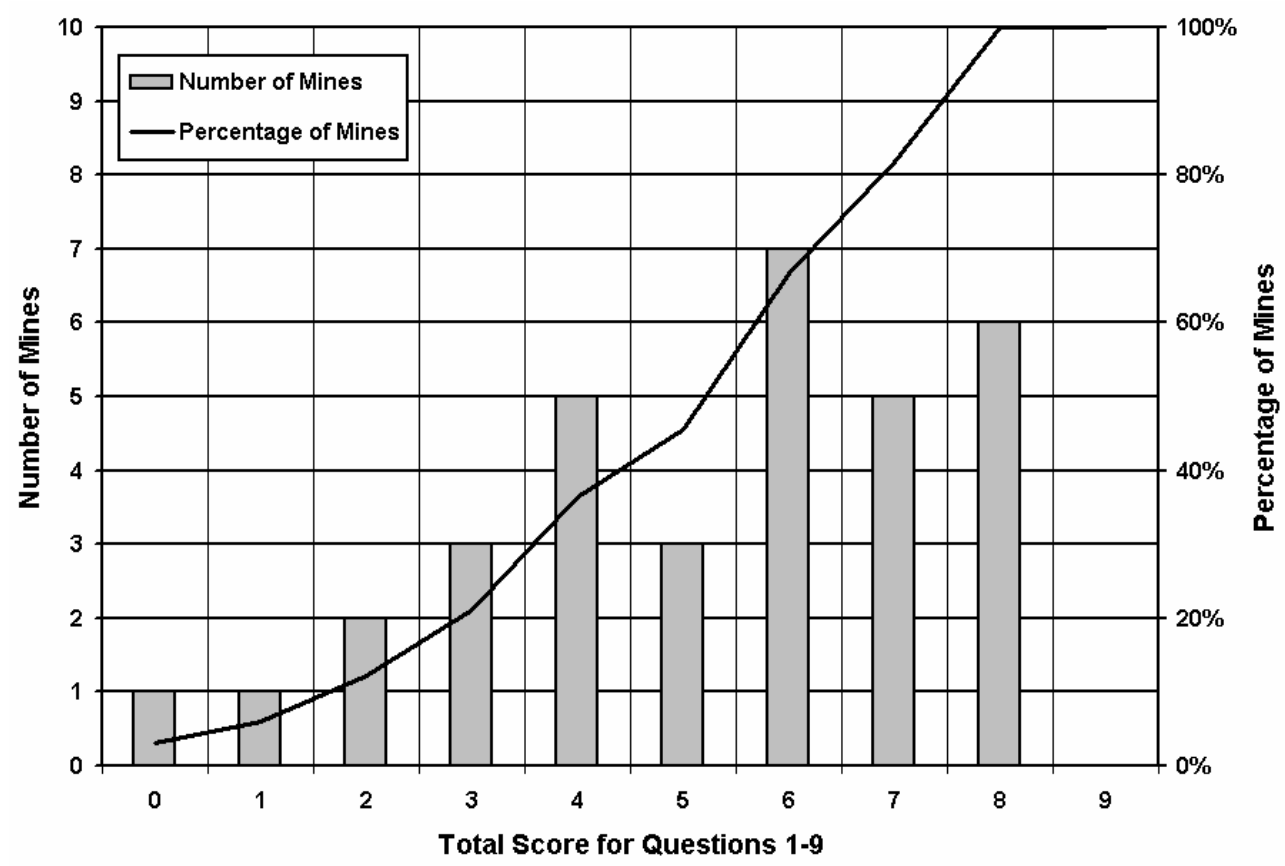

Figure 4 Results of the first 9 question, seismic monitoring and processing seismic data

\subsubsection{Seismic data analysis and interpretation}

Questions 10 to 20 of the survey focus on how seismic data is analysed and interpreted. Figure 5 is a histogram of the results from the mines, for these last 11 questions. The average score is 4.3. Within the context of the survey, a relatively poor score is less than 3 , and a relatively good score is more than 5 .

The relatively low scores in this part of the survey underline the fact that detailed seismic data analysis and interpretation is not commonly undertaken at minesites. Over the last 20 years, researchers have developed many techniques for detailed analysis of seismic data. However, most of these techniques are rarely performed at minesites.

Analysis of the individual questions gives insight into which techniques are most commonly applied (Figure 6). The only questions which received a positive response from more than $50 \%$ of the mines are: Question 10 - Seismic events are routinely plotted on mine plans, Question 18 - Seismic events are compared to numerical modelling results, and Question 19 - Seismic data and information are routinely used for mine planning decisions.

The questions that had the fewest positive responses were: Question 12 and Question 20. Both questions involve the use of frequency-magnitude relations for seismic hazard evaluation at mine sites. In both cases, only about 1 in 10 mines reported using frequency-magnitude relations. 


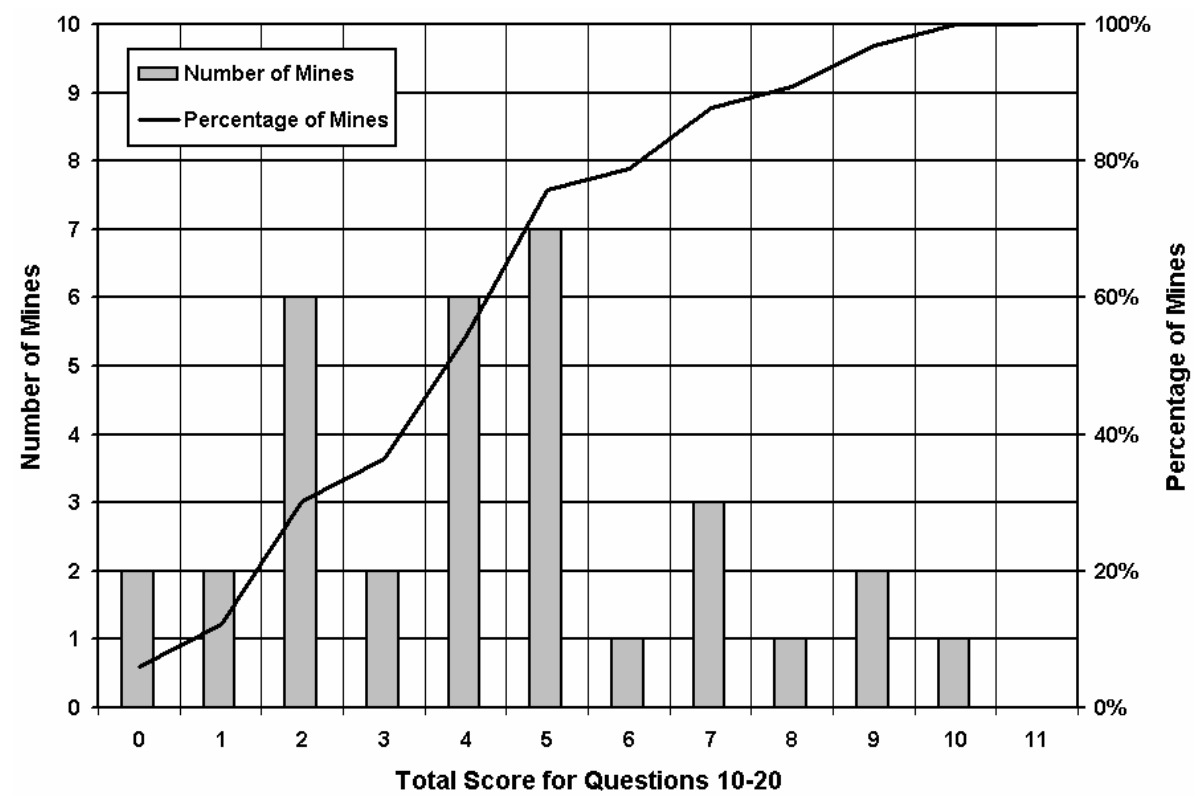

Figure 5 Results from questions 10 to 20, seismic data analysis and interpretation

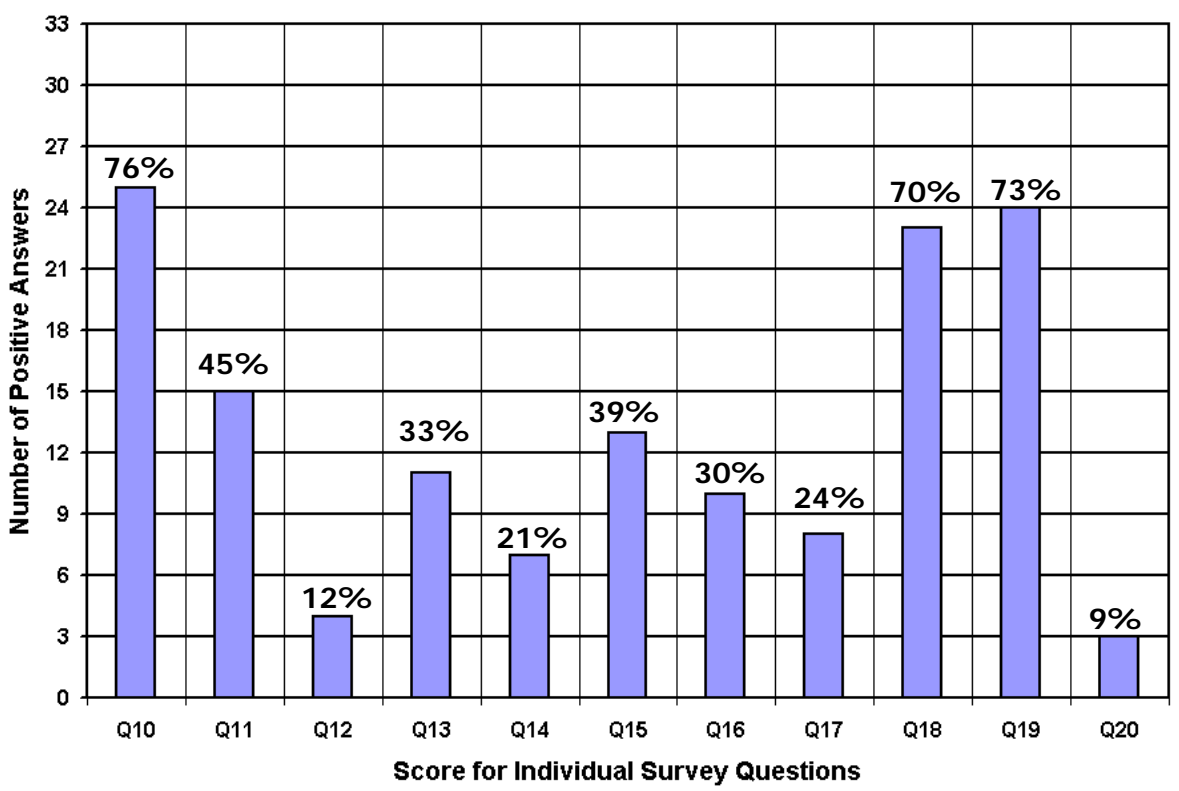

Figure 6 The number of mines which were answered positively for Questions 10 to 20

The data analysis technique the most commonly used is plotting events on up-to-date mine plans (76\%). While data is processed on a daily basis about $80 \%$ of the mines (Question $7-27 / 33$ ), only about $40 \%$ of the mines write monthly seismic reports (Question 15 -13/33).

Analysis techniques which require the use of significant time periods of seismic data are even less frequently used, Question 13 - identifying seismic sources (33\%), Question 14 - time history analysis (21\%), Question 17 - seismic source parameter analysis (24\%), and Question 20 - seismic hazard analysis $(10 \%)$. These are the techniques that have the potential to identify and understand future seismicity problems. Of particular surprise is that only 10 of the 33 mines, had developed formal re-entry procedures based on their seismic data (Question 16).

Essentially, a low score on Questions 10 to 20 implies that short-term re-active seismic analysis techniques are most commonly used. A higher score (in the range of six or seven or more) on Questions 10 to 20 suggests that longer term proactive analyses are routinely undertaken. 


\subsubsection{Generalisations}

In general, most mines have minewide seismic systems that are adequately calibrated and maintained, with the seismic data processed on a routine basis (Questions 1 to 9). Essentially, the day-to-day, reactive application of seismic monitoring is performed well.

However, routine detailed analysis of the seismic data is not undertaken. Proactive data analysis objectives such as identifying individual seismic sources in the mines, developing local re-entry procedures, investigating seismic source parameters, and actively looking for changes in event trends are applied in only 1 mine in 3. Analysis of frequency-magnitude relations, which is the basis of seismic hazard analysis, is applied in only about 1 mine in 10 .

There are a number of possible reasons why more proactive seismic analyses are not routinely undertaken, including:

- Acceptance. The analysis techniques are not widely accepted by minesite personnel and are perceived as not adding any value to the understanding of seismicity in mines.

- Training. The techniques are not being applied because minesite personnel do not believe they have adequate training and technical literature to undertake and interpret the analyses.

- Tools. Adequate analysis tools either don't exist, or are so difficult to use that they are discarded as not being useable.

- Time. The amount of time available to undertake more complex seismic analyses is not available or cannot be justified at the expense of other tasks.

With only about $25 \%$ of mines (8/33) scoring more than 5 on Questions 10 to 20 (Figure 5), the future direction to improve seismic monitoring at minesites is clear. For more proactive application of seismic data, seismological analysis and interpretation of recorded seismicity needs to be routinely undertaken.

\subsubsection{Benchmarking}

The data collected for the 33 mines can be used as a means of benchmarking seismic monitoring performance. Table 2 gives a relative comparison of the ASM score versus seismic system effectiveness, ranking compared to other mines, and a generalised description of how seismic data is applied at a mine.

\section{Conclusions}

A survey questionnaire has been developed that rates the application of seismic monitoring in a mine. A higher score is related to better use of seismic data and more proactive identification of seismic problems in a mine. A lower score implies that the seismic data is under utilised and the application of seismic monitoring information is purely reactive.

A survey was performed at 33 mines and it was found that the design and operation of seismic monitoring systems is generally good, however, detailed seismic data analysis is not widely undertaken. Despite the more than 20 years of research into mine seismology and seismic data analysis techniques, these techniques are not widely used in mines. The results of the survey suggest that greater emphasis needs to be put on showing the value of these techniques, and making their minesite application more user-friendly. 
Table 2 Generalised description of seismic monitoring effectiveness, based on the ASM survey

\begin{tabular}{|c|c|c|c|}
\hline $\begin{array}{l}\text { Survey } \\
\text { Rating }\end{array}$ & $\begin{array}{l}\text { Seismic } \\
\text { System } \\
\text { Effectiveness }\end{array}$ & $\begin{array}{l}\text { Percentile } \\
\text { Compared } \\
\text { to Other } \\
\text { Mines }\end{array}$ & $\begin{array}{c}\text { Generalised Description of the Application of the Seismic } \\
\text { Monitoring at the Mine }\end{array}$ \\
\hline $0-5$ & Poor & $\begin{array}{l}\text { Lower } \\
20 \%\end{array}$ & $\begin{array}{l}\text { - Seismic system is not well run and not an effective monitoring } \\
\text { tool. } \\
\text { - It is poorly utilised and purely a reactive system. } \\
\text { - This system is providing minimal value to the mining operation. }\end{array}$ \\
\hline $6-8$ & $\begin{array}{l}\text { Below } \\
\text { Average }\end{array}$ & $\begin{array}{c}20 \%- \\
40 \%\end{array}$ & $\begin{array}{l}\text { - System is adequately utilised but its application is essentially } \\
\text { only reactive. } \\
\text { - There is insufficient data analysis and interpretation, and no } \\
\text { significant proactive application of seismic data. } \\
\text { - The system is likely under-performing the original monitoring } \\
\text { objectives. }\end{array}$ \\
\hline $9-12$ & Average & $\begin{array}{l}40 \%- \\
70 \%\end{array}$ & $\begin{array}{l}\text { - System is generally well run and well maintained. } \\
\text { - Some data interpretation is undertaken. } \\
\text { - Much more can be done to proactively use the seismic data. }\end{array}$ \\
\hline $13-14$ & Good & $\begin{array}{l}70 \%- \\
90 \%\end{array}$ & $\begin{array}{l}\text { - System is very well run and maintained. } \\
\text { - Seismic data is generally well utilised. } \\
\text { - There is some proactive use of seismic data to understand } \\
\text { problems in the mine. } \\
\text { - More value can probably still be derived from the seismic data. }\end{array}$ \\
\hline $15-17$ & Very Good & $\begin{array}{l}90 \%- \\
95 \%\end{array}$ & $\begin{array}{l}\text { - Approaching world's best practice in operating, maintaining and } \\
\text { utilising seismic monitoring at mines. }\end{array}$ \\
\hline $18-20$ & Excellent & $\begin{array}{l}95 \%- \\
100 \%\end{array}$ & $\begin{array}{l}\text { - World's best practice in operating, maintaining and utilising } \\
\text { seismic monitoring in mines. }\end{array}$ \\
\hline
\end{tabular}

\section{Acknowledgements}

The authors wish to thank the mines that completed the "Application of Seismic Monitoring" survey, or provided data for the survey.

\section{References}

Amidzic, D. (2001) Energy-moment relation and its application. Proceedings Rockbursts and Seismicity in Mines RaSiM 5, Johannesburg, September 2001, G. van Aswegen, R.J. Durrheim and W.D. Ortlepp (eds), Johannesburg, South African Institute of Mining and Metallurgy, pp. 509-513.

Brummer, R.K. (1999) Simple truths about rockbursts. Proceedings SARES99, $2^{\text {nd }}$ South African Rock Engineering Symposium, Johannesburg, 13-15 September 1999, T.O. Hagan (editor), 6-11. Johannesburg.

Cronbach, L.J. (1951). Coefficient alpha and the internal structure of tests. Psychometrika, Vol. 16(3), pp. $297-334$.

Hudyma, M.R., Heal, D. and Mikula, P. (2003) Seismic monitoring in mines - old technology - new applications. Proceedings $1^{\text {st }}$ Australasian Ground Control in Mining Conference, Sydney, pp. 201-218.

Leslie, I. and Vezina, F. (2001) Seismic data analysis in underground mining operations using ESG's Hyperion systems. Proceedings $16^{\text {th }}$ Quebec Mining Association Ground Control Colloque, March 2001, Val D'Or.

Mendecki, A.J., van Aswegen, G. and Mountfort, P. (1999) A guide to routine seismic monitoring in mines. Chapter 9 in A Handbook on Rock Engineering Practice for Tabular Hard Rock Mines. A.J. Jager and J.A. Ryder (eds), Creda Communications, Cape Town.

Mikula, P.A. and Lee, M.F. (2002) Forecasting and controlling pillar instability at Mt Charlotte Mine. Proceedings $1^{\text {st }}$ International Seminar on Deep and High Stress Mining. Australian Centre for Geomechanics, Perth. 